\title{
Article
}

\section{The Measurement and Analysis of Impedance Response of HeLa Cells to Distinct Chemotherapy Drugs}

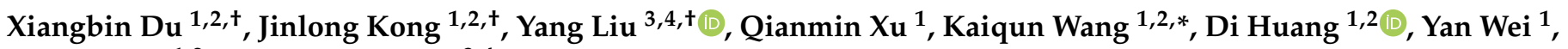 \\ Weiyi Chen ${ }^{1,2}$ and Haiyang Mao ${ }^{3,4, *}$ \\ 1 Department of Biomedical Engineering, Research Center for Nano-biomaterials \& Regenerative Medicine, \\ College of Biomedical Engineering, Taiyuan University of Technology, Taiyuan 030024, China; \\ duxiangbin@ime.ac.cn (X.D.); kongjinlong0787@tyut.edu.cn (J.K.); xuqianmin7113@link.tyut.edu.cn (Q.X.); \\ huangjw2067@163.com (D.H.); weiyan@tyut.edu.cn (Y.W.); chenweiyi@tyut.edu.cn (W.C.) \\ 2 Shanxi Key Laboratory of Material Strength \& Structural Impact, Institute of Biomedical Engineering, \\ Taiyuan University of Technology, Taiyuan 030024, China \\ 3 Institute of Microelectronics of Chinese Academy of Sciences, Beijing 100029, China; liuyang6@ime.ac.cn \\ 4 University of Chinese Academy of Sciences, Beijing 100049, China \\ * Correspondence: wangkaiqun@tyut.edu.cn (K.W.); maohaiyang@ime.ac.cn (H.M.); \\ Tel.: +86-139-3421-2990 (K.W.); +86-158-0125-6264 (H.M.) \\ + These authors contributed equally to this work.
}

check for updates

Citation: Du, X.; Kong, J.; Liu, Y.; Xu, Q.; Wang, K.; Huang, D.; Wei, Y.; Chen, W.; Mao, $\mathrm{H}$. The Measurement and Analysis of Impedance Response of HeLa Cells to Distinct Chemotherapy Drugs. Micromachines 2021, 12, 202. https://doi.org/10.3390/mi12020202

Academic Editor: Francesco Gentile

Received: 24 December 2020

Accepted: 13 February 2021

Published: 16 February 2021

Publisher's Note: MDPI stays neutral with regard to jurisdictional claims in published maps and institutional affiliations.

Copyright: (c) 2021 by the authors. Licensee MDPI, Basel, Switzerland. This article is an open access article distributed under the terms and conditions of the Creative Commons Attribution (CC BY) license (https:// creativecommons.org/licenses/by/ $4.0 /)$.

\begin{abstract}
Electric cell-substrate impedance sensing exhibits a real-time and label-free feature to monitor the response of cells stimulated by various biochemical and mechanical signals. Alterations in the currents passing through the cell-electrode system characterize the impedance variations of cells. The impedance responses of HeLa cells under distinct chemotherapy drugs combine the effects of cell proliferation and cell-substrate adhesion. Optimal interdigitated electrodes were selected to explore the impedance responses of HeLa cells. Measurements of impedance of cells in response to three widely used chemotherapy drugs in clinical practice, namely cisplatin, doxorubicin, 5-fluorouracil, were performed. The results demonstrated that distinct impedance responses of HeLa cells to drugs were exhibited and a decrease in measured impedance was observed after drug treatment, accompanied by alterations in the distribution and intensity of the adhesion-related protein vinculin and the rate of cell proliferation. The link between the impedance profiles of HeLa cells and their biological functions was developed based on the circuit model. This study demonstrated the weights of cell proliferation and adhesion of HeLa cells under the treatments of DDP, DOX, and 5FU, resulted in distinct impedance responses of cells, providing an impedance-based evaluation methodology for cervical cancer treatment.
\end{abstract}

Keywords: cellular impedance-based sensing; interdigitated electrodes; chemotherapy drug response; cell-electrode resistance; cell-cell resistance

\section{Introduction}

Electric cell-substrate impedance sensing (ECIS) is a label-free, noninvasive method for monitoring the physiological state of cells in real time by detecting changes in impedance. The electrical properties of cells are regarded as effective markers to explore the complex physiological states of cells [1]. ECIS-based measurements have widely provided real-time and noninvasive biophysical approach to monitor living cells in vitro. The viability of hypoxic cells was regulated by carbonic anhydrase IX inhibitors and well characterized by changes in the impedance of cells [2]. The effect of clinical bacteria isolates on the integrity of epithelial cells was evaluated based on a decrease in the impedance of cells [3]. Moreover, changes in regulatory factors or protein within cells affected cell impedance, for instance, vinculin-null cells exhibited lower cell impedance [4]; Amyloid- $\beta 42$ regulates cell adhesion via the TJ protein to regulate impedance of MDCK cells [5]. The ECIS technique provided useful information for estimating the fill factor of muscular stem cells [6]. This technique 
was also used in previous works to study tumor cell cycle [7], invasion [8], proliferation [9], and the interaction between tumor cells and other stromal cells [10]. Given the significant support of previous studies [4] that showed careful regulation of impedance responses of cells to various stimuli by vinculin-related attachment, in our work, we further combined the effects of cell proliferation and cell adhesion to explore the link between the alterations in impedance response of cells and biological changes of cells using optimized interdigitated electrodes (with the support of advanced simulations).

Numerous studies demonstrated that the impedance of electrodes is determined by the electrical properties of the electrodes, the adhesive degree between cells and the electrodes, and the proliferation of cells on the electrodes [11-13]. Low electrode impedance is required to reduce measurement noise, which is regulated by the type of electrode materials, morphology, and the size of the electrodes. Cell-mediated blocking of the area of the electrodes available for current flow may be complex. During the process of proliferation, MCF-7 exhibited a higher impedance response due to closer cell-cell contact [14]. BEAS-2B, A549, NCI-H292, and PBECs cells with different adhesion characteristics cause different impedance changes [15]. Cell adhesion and proliferation are associated with many cell functions and are regulated by various biochemical and mechanical stimulations. However, investigation of the relative weights of these two factors in regulating cell impedance responses is still insufficient.

Given the significant threat of cervical cancer to women's health, in our work, the HeLa cell line, a typical cervical cancer cell line, was utilized as an important example of impedance profiles responding to the treatments of three commonly used chemotherapy drugs in clinical practice. In this study, the weighted correlation of cell adhesion and cell proliferation with the impedance responses of HeLa cells treated with dose-dependent cisplatin (DDP), doxorubicin (DOX), and 5-fluorouracil (5-FU) were investigated. It was observed that DDP, DOX, and 5-FU regulated cell proliferation and adhesion via distinct mechanisms [16-18]. DDP could inhibit DNA replication, DOX inhibits the activity of topoisomerase II, and 5-FU affects thymine synthase. The different weighted roles of cell proliferation and adhesion due to the treatment with DDP, DOX, and 5-FU [19-21] resulted in different impedance responses of HeLa cells under drug treatment. The interdigitated electrodes were designed and fabricated to monitor the impedance of the HeLa cells, and the optimal performance of the electrodes was selected to explore the distinct responses of the HeLa cells treated using different chemotherapy drugs. Drug-mediated cell adhesion and cell proliferation were measured to investigate the drug responses of the HeLa cells. The cell-electrode circuit model was then used to extract the electrical parameters of the HeLa cells to interpret the weighted correlation of cell adhesion and cell proliferation with the impedance responses of the HeLa cells under chemotherapy stimulation. This work demonstrates that the impedance responses of cells could act as a significant biomarker to evaluate the efficacy of chemotherapy drugs, thereby facilitating clinicians to obtain more accurate feedback on patient response to drugs. Additionally, the real-time and label-free impedance tests could shorten the efficacy evaluation cycle of drugs in order to initiate treatment as soon as possible.

\section{Materials and Methods}

\subsection{Materials and Reagents}

Dulbecco's modified Eagle medium (DMEM) and fetal bovine serum (FBS) were obtained from Gibco (Carlsbad, CA, USA). Matrigel Matrix was obtained from BD Biosciences (Bedford, MA, USA). CCK-8 was purchased from Dojindo (Kumamoto, Japan). Penicillin and streptomycin were purchased from Thermo Fisher (Waltham, MA, USA). DAPI was obtained from Beyotime (Suzhou, China). Cisplatin (DDP, $\geq 99 \%$, Sigma, St. Louis, MO, USA), doxorubicin (DOX, $\geq 99 \%$, Sigma, St. Louis, MO, USA), 5-fluorouracil (5-FU, $\geq 99 \%$, Sigma, St. Louis, MO, USA), anti-vinculin antibody, and CF 488A-labeled goat anti-mouse IgG secondary antibody were purchased from Sigma (St. Louis, MO, USA). 
Both the chemical reagents used in the experiments were analytic reagents, and all solvents used in the experiments were deionized water.

\subsection{Interdigitated Microelectrodes: Fabrication and Simulation}

The ECIS-based microelectrodes were fabricated by metal lift-off techniques, as shown in Figure 1a. To start the process, AZ6130 photoresist was spin-coated on a glass substrate and then patterned by UV exposure. Then, a layer of Au was sputtered onto the surface of the photoresist. Later, micropatterns of the Au electrodes were formed using the lift-off technique. Finally, a customized PDMS culture well was glued around the microelectrodes. Figure $1 b$ shows the configuration of the electrodes.

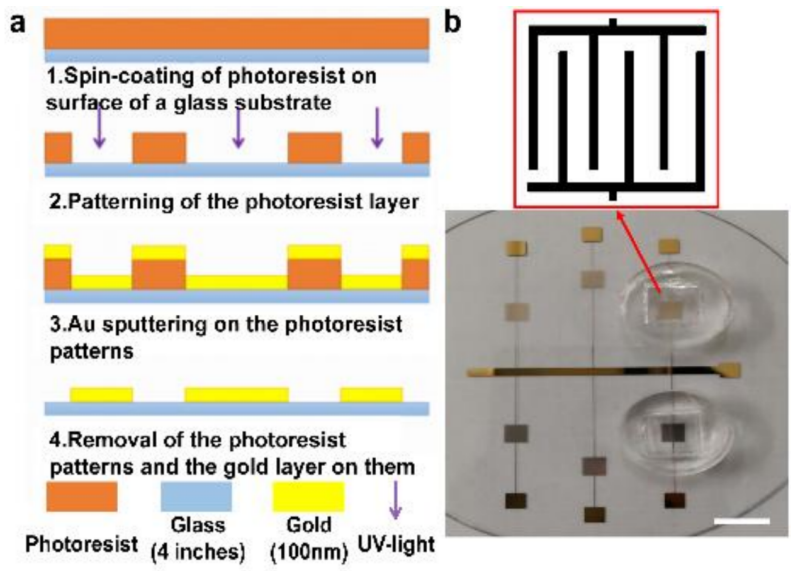

Figure 1. (a) Fabrication processes of the electric cell-substrate impedance sensing (ECIS)-based sensor. (b) Configuration of the prepared ECIS-based sensor. Scale bar $=1 \mathrm{~cm}$.

It is essential to optimize structural parameters of the electrodes to obtain the higher sensitivity of monitoring cell status. It was observed that a finger width and finger-finger spacing of the electrodes affected the performance of the electrodes [22-24]. In our study, changes in the density of the currents passing through the electrodes were explored before and after addition of cells on the top of electrodes to select the electrodes with the optimal performance. We designed four kinds of interdigitated electrodes (IDEs) with different sizes. Finite element method (FEM) was conducted to investigate the influence of electrode size on the performance of IDEs. The FEM model of the electrodes using DMEM is shown in Figure 2. The model consisted of three components, including the IDEs, the culture medium, and cells, and was simulated using the AC/DC module in COMSOL, with an input voltage of $0.5 \mathrm{~V}$ at $40 \mathrm{~Hz}$. The medium was characterized by a solid element, with a conductivity of $1.38 \mathrm{~S} / \mathrm{m}$ and a relative permittivity of 80 , then placed on top of the electrodes. Cells, with a diameter of $15 \mu \mathrm{m}$, a conductivity of $0.32 \mathrm{~S} / \mathrm{m}$, and a relative permittivity of 5000 , were located on the top of the electrodes.

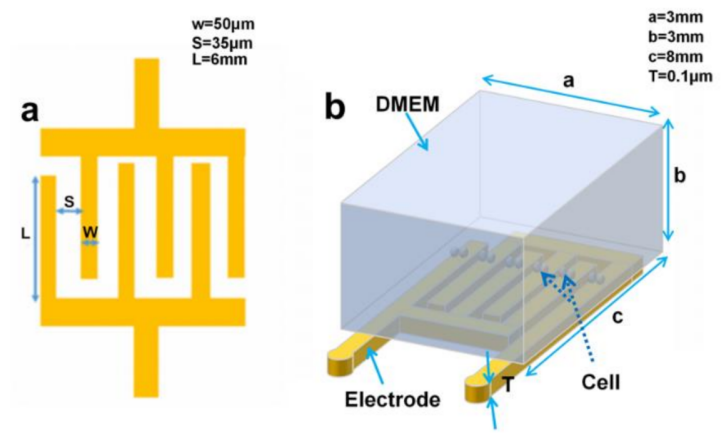

Figure 2. Schematic finite element method (FEM) model of interdigitated microelectrodes, Dulbecco's modified Eagle medium (DMEM), and cells. 


\subsection{Cell Experiments}

\subsubsection{Cell Culture}

HeLa human cervical carcinoma cells (ATCC number: CCL-2, Gaithersburg, MD, USA) were cultured in DMEM supplemented with $10 \% \mathrm{FBS}, 1 \%$ penicillin, and streptomycin, and incubated at $37{ }^{\circ} \mathrm{C}$ in a humidified incubator with $5 \% \mathrm{CO}_{2}$. After $48 \mathrm{~h}$, the HeLa cells were passaged by trypsin, digested, and diluted to appropriate concentrations for subsequent experiments.

\subsubsection{Impedance Response Measurement of HeLa Cells}

The coated electrodes were sterilized by soaking them in alcohol under UV light for several hours. Matrigel was diluted with serum-free medium (1:8) and evenly coated onto the surface of the microelectrode substrate to form the gel film. HeLa cells were cultured on the substrate coated with Matrigel at a density of $3 \times 10^{5}$ cells/well for $24 \mathrm{~h}$. The impedance response was taken using an LCR meter (IM3536, HIOKI, Nagano-ken, Japan). The process of impedance measurement is illustrated in Figure 3. The optimal detection frequency of impedance was measured corresponding to the peak value of the normalized impedance, which is defined as follows [22]:

$$
Z_{\text {norm }}=\frac{Z_{\text {cell }}(f)}{Z_{\text {cell }- \text { free }}(f)}
$$

where $Z_{\text {cell }}$ is the total impedance of the cell-electrode system and $Z_{\text {cell-free }}$ is the impedance of the electrodes without cell blocking.

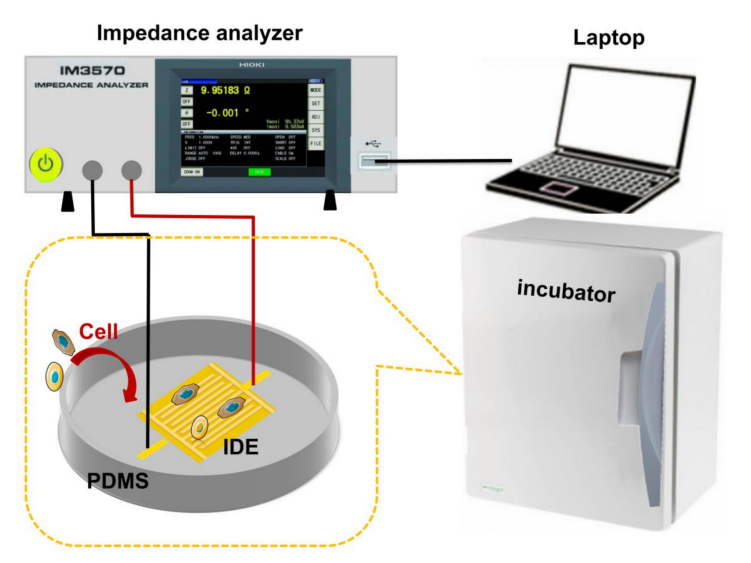

Figure 3. Schematics of impedance measurement of HeLa cells. HeLa cells were placed in the PDMS-enclosed well and then incubated at $37^{\circ} \mathrm{C}$ and $5 \% \mathrm{CO}_{2}$. The impedance of the HeLa cells was monitored in real time.

After $24 \mathrm{~h}$ of HeLa cell growth on the surface of the microelectrodes, 40 and $80 \mu \mathrm{g} / \mathrm{mL}$ DDP, 40 and $80 \mu \mathrm{g} / \mathrm{mL}$ DOX, and 400 and $800 \mu \mathrm{g} / \mathrm{mL}$ 5-FU were added into culture wells, respectively. The concentrations of DDP, DOX, and 5-FU utilized in the experiment were derived from previous studies [25-27]. Drug-treated HeLa cells were continuously incubated for $24 \mathrm{~h}$ and untreated HeLa cells were taken as the control group. The impedance profiles of HeLa cells treated by distinct dose-dependent drugs were monitored per hour at the optimal frequency. The measured responses were characterized by the cell index (CI) using the following expression [28]:

$$
C I=\frac{Z_{\text {cell }}-Z_{\text {cell-free }}}{Z_{\text {cell }- \text { free }}}
$$




\subsubsection{Cell Viability Assay}

HeLa cells were incubated at a concentration of $3 \times 10^{5}$ cells $/$ well and cultured in a 96-well plate for $24 \mathrm{~h}$, followed by the treatment of three chemotherapy drugs for further culture for $24 \mathrm{~h}$. The CCK-8 reagent was added to each well, and cells were then incubated for $4 \mathrm{~h}$. Finally, the absorbance (OD) of each well at $450 \mathrm{~nm}$ was determined by an enzyme marker. The measurements were repeated three times.

\subsubsection{Immunofluorescence Staining}

HeLa cells treated by DDP, DOX, and 5-FU were incubated in confocal Petri culture dishes for $24 \mathrm{~h}$, respectively. First, HeLa cells were fixed with $4 \%$ polyformaldehyde for $20 \mathrm{~min}$ and washed with PBS three times. Then, cells were permeabilized with $0.5 \%$ Triton $x-100$ and washed with PBS three times again. Subsequently, mouse monoclonal antivinculin antibody diluted with PBS (1:200) was added into the cell solutions and maintained overnight at $4{ }^{\circ} \mathrm{C}$. Next, CF 488A-labeled goat anti-mouse IgG secondary antibody diluted with PBS (1:500) was added into the cell solutions and maintained for $1 \mathrm{~h}$. Finally, the nuclei of the HeLa cells were stained with DAPI for $15 \mathrm{~min}$ to label the cells. Stained HeLa cells were observed under a confocal microscope (FV-1000, Olympus, Tokyo, Japan), and cells without drug treatment were observed as the control group. Experiments were conducted three times and the results were averaged.

\subsubsection{Measurement of the Number of Attached Cells Treated by Drugs}

In order to exactly reflect changes in the number of cells attached to the substrate due to the treatment of chemotherapy drugs, drug-treated cells were resuspended and reattached to the substrate and then the unattached cells were gently rinsed to better evaluate the number of attached cells. Treated HeLa cells were resuspended and reattached to the Matrigel-coated culture dish. Matrigel was coated on the 96-well plate at $37^{\circ} \mathrm{C}$ for $1 \mathrm{~h}$, then blocked with $1 \%$ BSA at $37^{\circ} \mathrm{C}$ for $1 \mathrm{~h}$. HeLa cells were treated with DDP, DOX, and 5-FU for $24 \mathrm{~h}$ and then digested and counted. Cells were resuspended in serum-free medium at a density of $8 \times 10^{4}$ cells $/ \mathrm{mL}$, with $0.1 \mathrm{~mL}$ of cell solution added to each well of the prepared 96-well plates and incubated at $37^{\circ} \mathrm{C}$ for $1 \mathrm{~h}$. Next, unattached HeLa cells were washed out in each well with PBS. Subsequently, $10 \mu \mathrm{L}$ of CCK-8 solution was added into each well for $3 \mathrm{~h}$ at $37^{\circ} \mathrm{C}$, then the absorbance values of the medium were measured at $450 \mathrm{~nm}$. The measurements were repeated three times.

\subsection{Statistical Analysis}

The experimental results were averaged. Tukey's significance test was used to evaluate the statistical differences between the different groups. Significant differences of results between two groups were marked by ${ }^{*}(P<0.05),{ }^{* *}(P<0.01)$, and ${ }^{* *}(P<0.001)$.

\section{Results}

\subsection{Screening of Experimental Conditions for Impedance Measurement}

The ECIS measurements reflected changes in the impedance of the electrodes according to AC current over time.

Higher current flow promoted sensitivity of the impedance sensor for detection [29]. Poor cell conductivity caused the current to bypass the cell region as the cell grows on the electrodes. Therefore, the distribution of the currents passing through the electrodes could be altered. In FEM simulation, biological cells were added on the top of the electrodes. It was shown that the magnitude and distribution of the current passing through the cross section of the electrodes were altered (Figure 4a). The current density could be reduced where cells are placed due to poor conductivity of cells, as shown by the red arrows in Figure 4a. We integrated the current density along the direction of the black arrow shown in the figure to obtain the total current through the cross section of the electrodes. Cells with the same number were added on the distinct electrodes. Figure $4 \mathrm{~b}$ exhibits the difference in the integrated current density over the section of the electrodes before and 
after addition of HeLa cells. The higher difference indicated the electrodes were more sensitive to cell response. A more obvious electrical response of cells could be observed in the electrodes with a finger width of $50 \mu \mathrm{m}$ and finger-finger spacing of $35 \mu \mathrm{m}$ in the case of the same input (cells). It was concluded that the electrodes with such structural parameters had higher sensitivity for monitoring changes in cell impedance. Figure $4 \mathrm{c}$ shows the experimental absolute impedance $|\mathrm{Z}|$ value of the selected electrodes with DMEM as a function of the detection frequency. The electrodes used in this study possessed low base impedance. For instance, the $|\mathrm{Z}|$ of the electrodes was around $1.2 \mathrm{k} \Omega$ at a frequency of $20 \mathrm{~Hz}$, which was appropriate for conduction of the subsequent experiment using the selected electrodes.

(a)
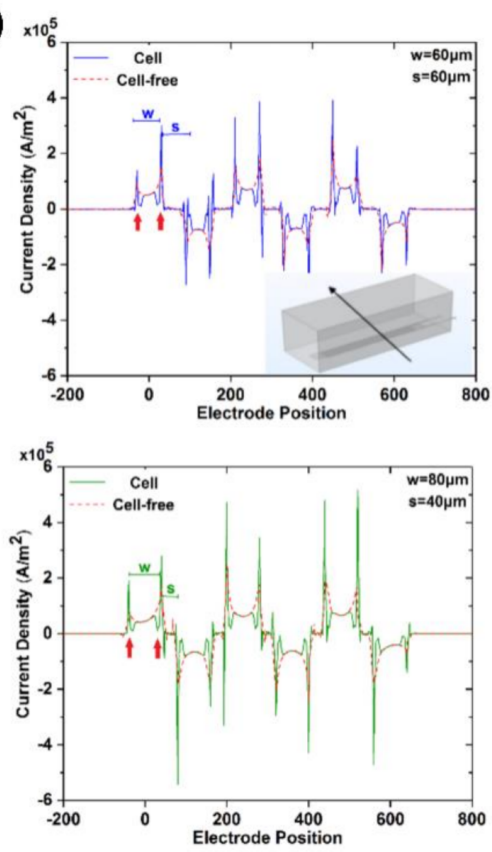
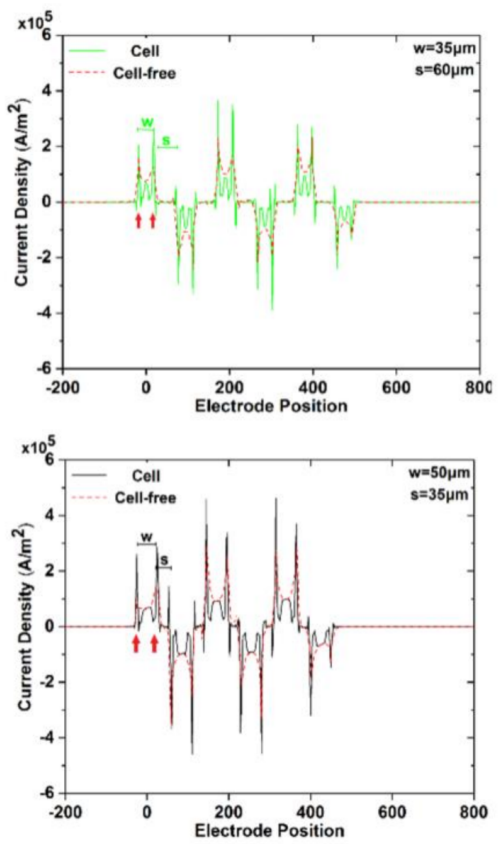

(b)

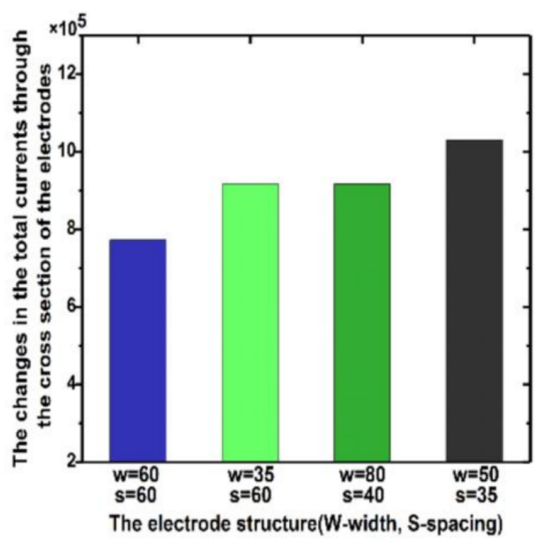

(c)

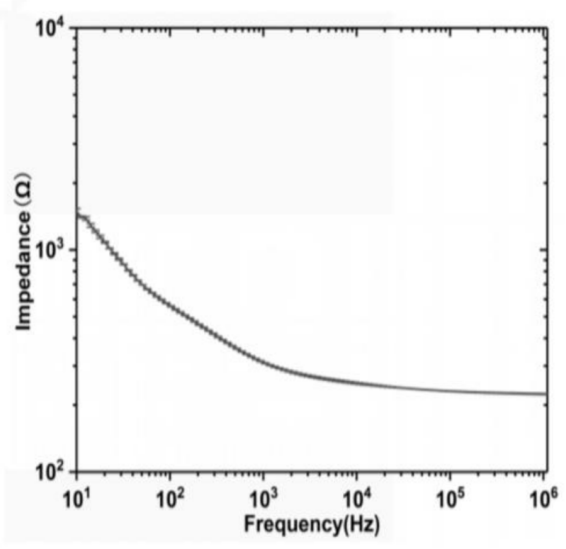

Figure 4. (a) Changes in current density passing through the cross section of the electrodes with different dimensions. (b) The differences of the total currents through the cross section of the electrodes before and after addition of cells on the top of the electrodes. (c) The experimental absolute impedance $|Z|$ value of the selected electrodes, with DMEM as a function of frequency.

Changes in the impedance response of cells could be associated with the sensitivity of the electrodes, the type of cells, and biological processes that cells undergo. It was indicated 
that the impedance of the electrodes was dependent on the detection frequency. We investigated the optimal detection frequency of the electrodes with HeLa cells. The HeLa cells were incubated on the electrode substrate for $24 \mathrm{~h}$, then the normalized total impedance as a function of the detection frequency was measured, as shown in Figure 5. The experimental results predicted that the maximum normalized total impedance was measured at a frequency of $4 \mathrm{kHz}$. Therefore, the impedance responses of the HeLa cells to chemotherapy drugs were explored at the optimal frequency.

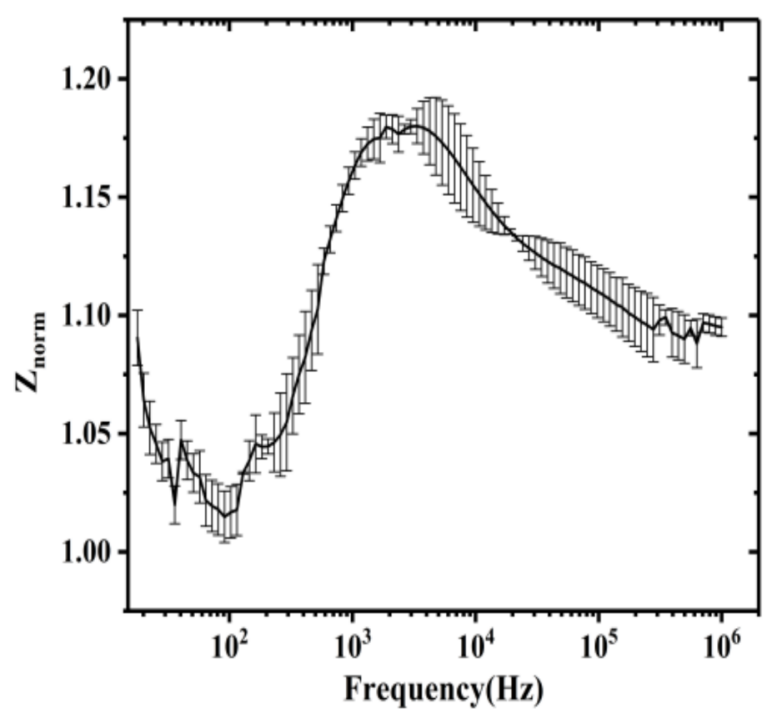

Figure 5. The normalized impedance of the electrodes with HeLa cells as a function of the detection frequency.

\subsection{Real-Time Impedance Response of HeLa Cells to Chemotherapy Drugs}

The distinct normalized impedance profiles of HeLa cells responding to the treatment of DDP, DOX, and 5-FU at a frequency of $4 \mathrm{kHz}$ and a current of $1.05 \mathrm{~mA}$ are shown in Figure $6 \mathrm{a}-\mathrm{c}$. The cell indexes of drug-treated cells and their control groups at different time points were normalized by taking the value of cell index of the drug-treated groups at the 24th hour as a baseline, respectively. The normalization method was derived from previous studies [30-33]. Over the first five hours, HeLa cells rapidly attached to the substrate and the increase of attached cells on the electrodes promoted the increase of the cell index rather than cells outside the electrode. From the 5th hour to the 24th hour, the cell index continued to increase at a slower rate compared to the initial stage. Increasing numbers of cells could have attached to the substrate, and attached cells were probably randomly distributed on or outside the electrodes. After $24 \mathrm{~h}$ of cell growth, DDP, DOX, and 5-FU at effective doses were added into the cell samples, respectively. The time points at which the cell index started to decrease were dependent on the type of chemotherapy drug and dose. The cell indexes of DDP-treated HeLa cells began to decline at the 27th hour and the 25th hour at concentrations of 40 and $80 \mu \mathrm{g} / \mathrm{mL}$, respectively. When HeLa cells were treated with 40 and $80 \mu \mathrm{g} / \mathrm{mL}$ DOX, the decreases in cell indexes occurred at the 38th hour and the 35th hour. Cell indexes of HeLa cells treated with 5-FU continued to increase at a very slow rate until about 16 hours after the drug was added, meaning that 5-FU-treated cells at doses of 400 and $800 \mu \mathrm{g} / \mathrm{mL}$ exhibited decreased cell indexes at the 43rd hour and the 40th hour, respectively. Cell indexes of the DDP-treated HeLa cells declined rapidly between the 25th hour and the 35th hour, then at a slower rate after the 35th hour. Treatment with DOX decreased the cell index rapidly and in a linear fashion. Cell indexes of 5-FU-treated HeLa cells decreased gradually at a slow rate. The time-integrated cell index responses represent an integration of the area under the cell index versus time curve, as shown in Figure $6 \mathrm{~d}-\mathrm{f}$. The time-integrated impedance output of HeLa cells was dependent on the amplitude and duration of the cell index and could be characterized as a marker to evaluate drug efficacy. 
The responses were integrated from the 24th hour to the 48th hour. It was observed that HeLa cells were more sensitive to DDP than DOX and 5-FU, with further increases in drug concentrations seeming to have limited effect on the impedance responses of HeLa cells to drug treatment. The HeLa cells exhibited an obviously delayed response to 5-FU treatment, with the cell index continuing to increase from the 24th hour to the 36th hour $(800 \mu \mathrm{g} / \mathrm{mL})$ and the 42 nd hour $(800 \mu \mathrm{g} / \mathrm{mL})$, therefore, the integrated cell indexes of the 5-FU-treated HeLa cells were similar.

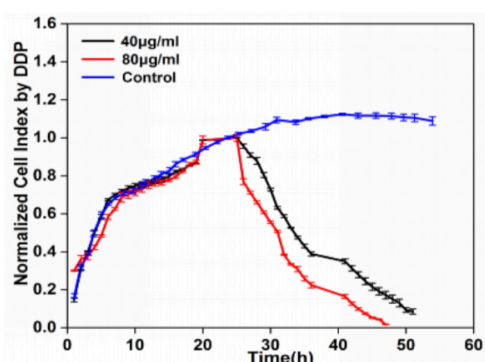

(a)

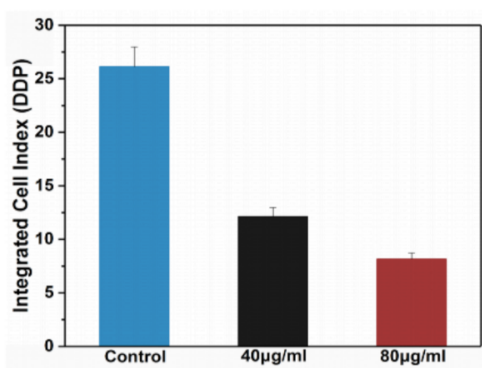

(d)

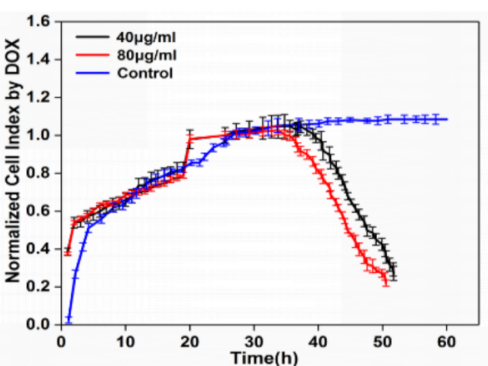

(b)

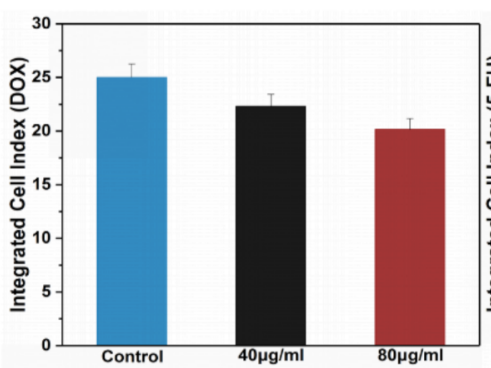

(e)

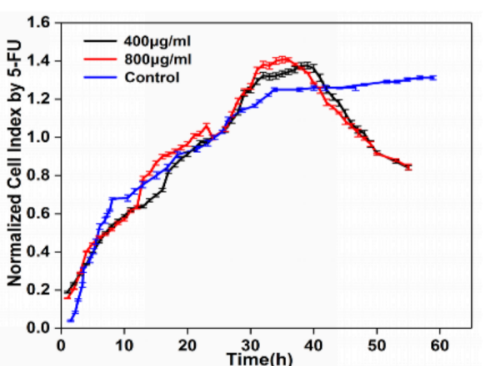

(c)

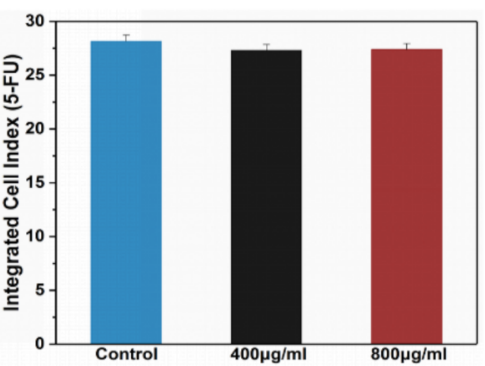

(f)

Figure 6. Real-time impedance profiles of HeLa cells treated with (a) 40 and $80 \mu \mathrm{g} / \mathrm{mL}$ cisplatin (DDP), (b) 40 and $80 \mu \mathrm{g} / \mathrm{mL}$ doxorubicin (DOX), and (c) 400 and $800 \mu \mathrm{g} / \mathrm{mL}$ 5-fluorouracil (5-FU). Chemotherapy drugs were added at $24 \mathrm{~h}$. (d-f) Time-integrated cell index responses of HeLa cells for drug treatments.

Measurements of cell viability were performed to explore distinct dose-dependent percentages of viable HeLa cells treated with DDP, DOX, and 5-FU for $24 \mathrm{~h}$, respectively, as shown in Figure 7. DDP at an effective dose imposed the most obvious inhibitory effect on the viability of HeLa cells, followed by DOX, with 5-FU exhibiting the lowest inhibitory function. The ratios of viable HeLa cells treated with 40 and $80 \mu \mathrm{g} / \mathrm{mL}$ DDP for $24 \mathrm{~h}$ to those without drug treatment were $34 \%$ and $21 \%$, respectively. The respective cell indexes of DDP-treated HeLa cells with the abovementioned concentrations at $48 \mathrm{~h}$ (corresponding to $24 \mathrm{~h}$ treatment of DDP) were around $25 \%$ and $14 \%$ of the control group. The impedance responses of the HeLa cells treated with DDP therefore appeared to be stronger than in the CCK8-based viability assay. A similar trend was observed for DOX-and 5-FU-treated HeLa cells, indicating that impedance-based cell responses are associated with cell viability, cell adherence, and other factors [34]. Cell viability tests were performed $24 \mathrm{~h}$ after treatment of drugs, as indicated in Figure 7, probably including some cells samples that were still alive but not in good condition (e.g., poor adhesion to the substrate). In the following section, analysis of the cell attachment investigations is discussed.

\subsection{Changes in Distribution and Intensity of Vinculin after Treatment with Chemotherapy Drugs}

Many studies demonstrated that chemotherapy drugs regulated the expression of adhesion-related proteins $[35,36]$. Vinculin, which directly binds to the cytoskeleton of cells, is one of the crucial components of focal adhesion (FA). Expression of vinculin was previously indicated to mediate cell adhesion and cell migration [37-39]. The distance between cells and the substrate was extended due to a decrease in vinculin level, with more 
current flow passing through the gap between the cells and the electrodes. The correlation between the impedance responses of the cells and the attachment of cells was investigated. Figure 8a exhibits the dose-dependent distributions of the vinculin of the HeLa cells after $24 \mathrm{~h}$ of treatment with DDP, DOX, and 5-FU, respectively. Compared with the control group, the vinculin of HeLa cells treated with DDP at concentrations of 40 and $80 \mu \mathrm{g} / \mathrm{mL}$ were more obviously distributed on the periphery of cells, particularly in the treatment of $40 \mu \mathrm{g} / \mathrm{mL}$ DDP. A similar trend was also observed in HeLa cells treated with 400 and $800 \mu \mathrm{g} / \mathrm{mL} 5$-FU, respectively. Vinculin of HeLa cells treated with $40 \mu \mathrm{g} / \mathrm{mL}$ DOX was almost evenly distributed within the cells. Distribution of vinculin under the treatment of $80 \mu \mathrm{g} / \mathrm{mL}$ DOX was similar to that in the control group. Changes in the expression of vinculin of HeLa cells are characterized by the fluorescence intensity of vinculin. The mean intensity of vinculin is shown in Figure 8b. The intensity of the vinculin in the HeLa cells was significantly enhanced after treatment with DDP, DOX, and 5-FU, particularly at lower concentrations, demonstrating that the tumor microenvironment provided a refuge for the tumor cells, which reduced their sensitivity to chemotherapy drugs by changing their adhesion behavior $[40,41]$. Thus, the upregulated expression of vinculin of HeLa cells treated with lower concentrations could be performed to resist drug toxicity. High-dose drug toxicity could outstrip the ability of HeLa cells to resist, resulting in deceased vinculin expression [42]. High expression of vinculin was shown to promote the stabilization of focal adhesion and inhibit cell migration $[43,44]$. We therefore assume that high expression of vinculin of HeLa cells treated with chemotherapy drugs could stabilize HeLa cells.

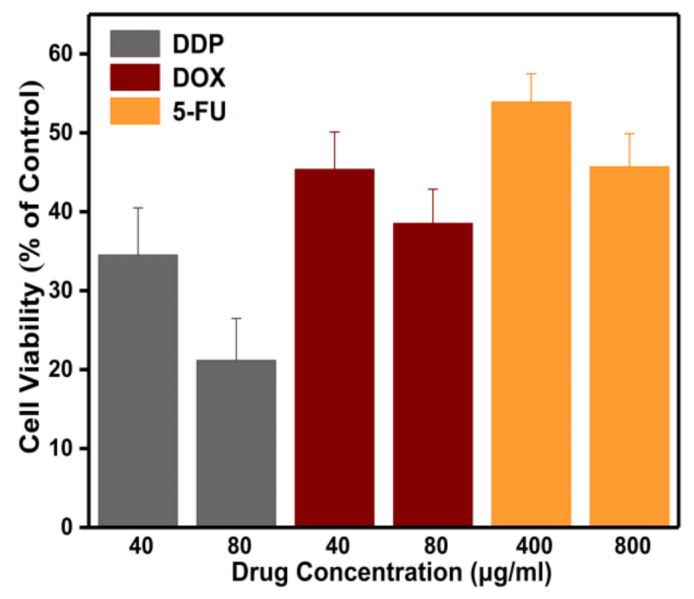

Figure 7. Viability of HeLa cells by dose-dependent DDP, DOX, and 5-FU for $24 \mathrm{~h}$. Cell viability is represented by the ratio of the absorbance (OD) values of cells treated with drugs to the OD values of the control group.

\subsection{Changes in the Number of Attached HeLa Cells Treated with Chemotherapy Drugs}

The impedance responses of the HeLa cells to the chemotherapy drugs were closely associated with cells cultured on the surfaces of the electrodes. Attached HeLa cells were measured after treatment with DDP, DOX, and 5-FU, respectively, for $24 \mathrm{~h}$. Figure 9 indicates that all three chemotherapy drugs with increased concentrations showed corresponding decreases in the numbers of attached HeLa cells. A minimal number of DDP-treated HeLa cells is shown compared with the number of cells treated by DOX and 5-FU. Based on the principle of impedance measurement, cells on the surfaces of the electrodes could disrupt the electrode-electrolyte interface and further regulate the whole impedance of the system. Inhibition of the proliferation of drug-treated HeLa cells grown on the electrodes could result in lack of cell contact with the electrodes. 
(a)

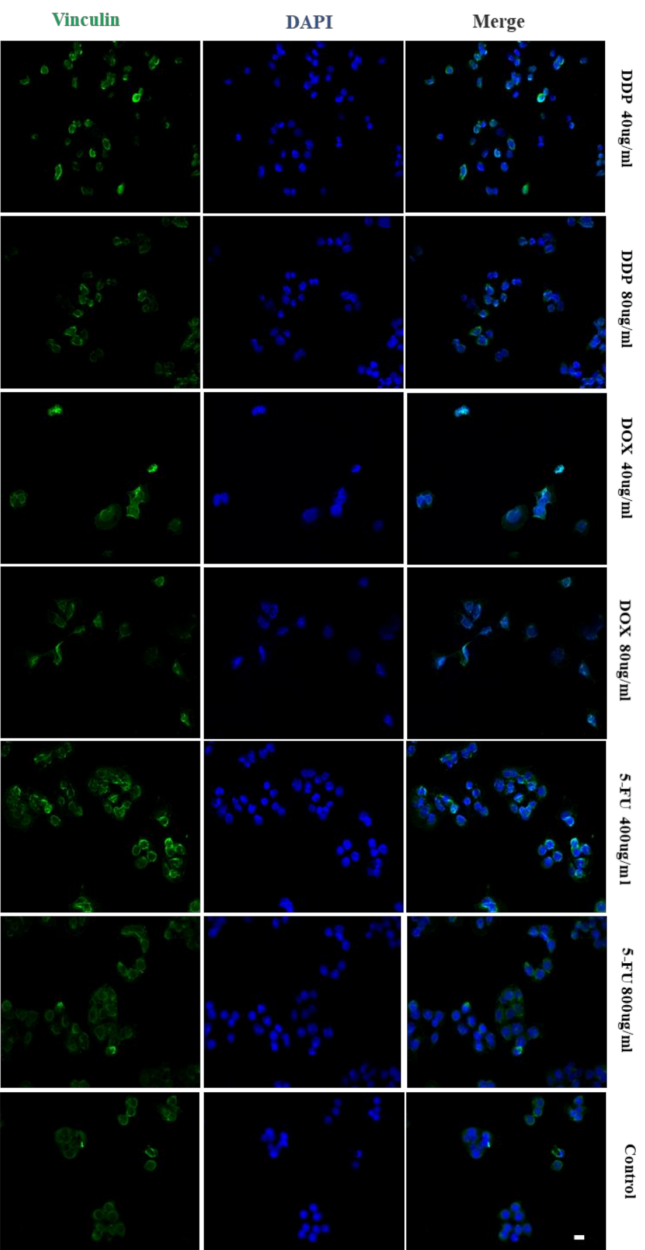

(b)

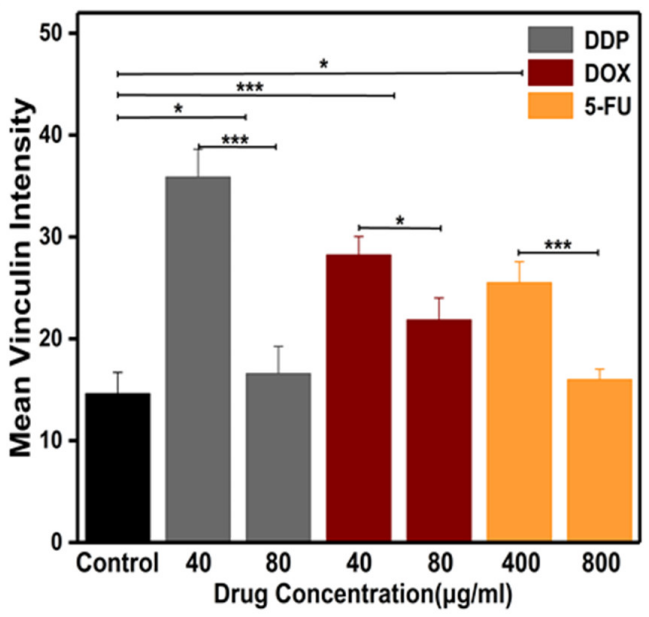

Figure 8. (a) Distribution of vinculin of HeLa cells treated by dose-dependent DDP, DOX, and 5-FU for 24 h; vinculin (green), DAPI (blue). (b) Average fluorescence intensity of vinculin. Scale bar: $20 \mu \mathrm{m}$.

ECIS-based measurement detected changes in the impedance of the electrodes to AC current flow over time. When cells were cultured on the surface of the electrodes, the area of the electrodes was blocked, forcing the current on the electrode/electrolyte interface to flow through the cell bodies and cell-cell gaps. Given alterations in the behavior of the attached HeLa cells treated with DDP, DOX, and 5-FU as mentioned above, the cellelectrode electrical circuit model was utilized to extract the electrical properties of the 
drug-treated Hela cells. It was demonstrated that the currents could pass through cells, cell-cell gaps, and cell-substrate gaps in the process of ECIS testing [45]. Additionally, it was indicated that the current would flow through the cells after flowing through the cell-substrate gaps [46]. The model exhibited biological cell electrical behavior in series with the electrodes, as shown in Figure 10a. The electrical behaviors of the electrodes and cells are represented by Randles's circuit with a Warburg element and RC circuit $[47,48]$. CPE was constant phase element, $R_{c t}$ denoted charge transfer resistance, and $R s$ represented medium resistance. This circuit model establishes the link between the electrical properties of the cells and their biological functions. The impedance responses of the HeLa cells reflected integrated drug efficacy, providing a potential marker of drug efficacy evaluation. The increase in cell number decreased the intercellular distances, leading to less current flow passing through the intercellular distances. On the other hand, larger intercellular distances caused by the inhibition of cell proliferation increased the current flow passing through the intercellular distances. In our circuit model, the resistance, $R_{\text {cell }}$, reflected changes in the current flow passing intercellularly. Therefore, changes in the numbers of cells treated with chemotherapy drugs were characterized by the resistance $R_{\text {cell }}$. Higher $R_{\text {cell }}$ values represented cell proliferation. Based on this study, the expression levels of vinculin, an important focal adhesion protein, of cells treated with chemotherapy drugs were altered, indicating changes in adhesion between cells and the substrate regardless of the region, for example, the electrode region or the area between the electrodes. Hence, the distance between the cells and the substrate could be extended due to decreased vinculin, with more current flow passing through the gaps between cells and the electrodes. The resistance, $R_{s}^{\prime}$, reflected these changes in the current flow passing through these regions. Higher values of $R_{s}^{\prime}$ represented higher cell-electrode adhesion [49].

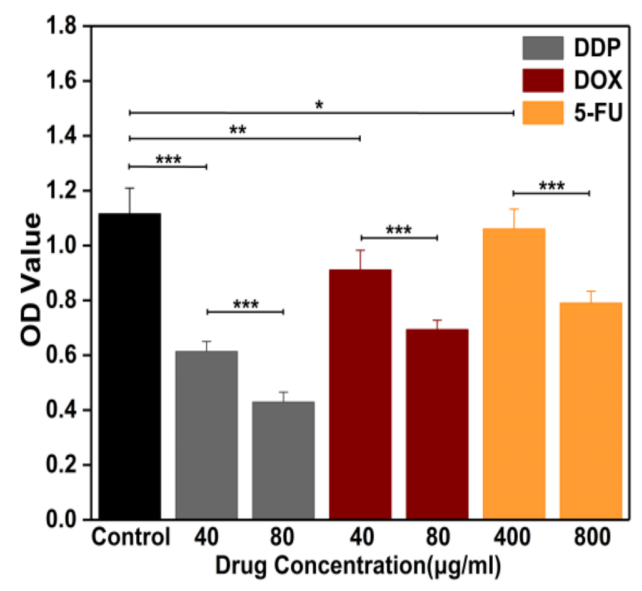

Figure 9. Proliferation of HeLa cells treated dose-dependently with DDP, DOX, and 5-FU based on the CCK-8 assay.

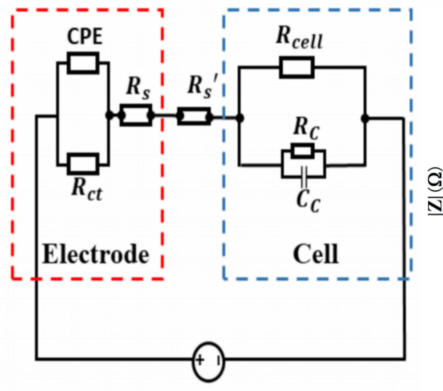

(a)

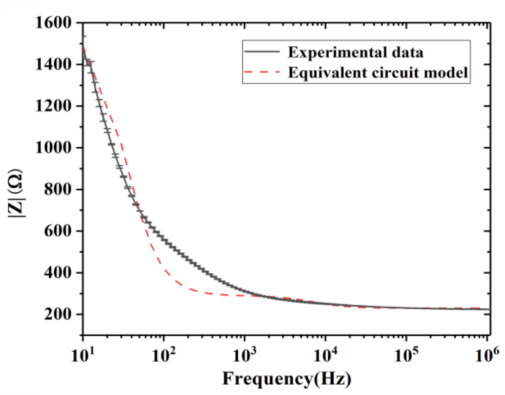

(b)

Figure 10. (a) Equivalent circuit model of the cell-electrode impedance test system. (b) Equivalent circuit fitting result. 
We further investigated the correlation between impedance responses and cell-cell or cell-electrode contact of HeLa cells treated with dose-dependent DDP, DOX, and 5-FU at $48 \mathrm{~h}$, corresponding to $24 \mathrm{~h}$ of drug treatment. The values of each electrical element of the electrodes were derived by fitting with the experimental impedance-frequency curve of the electrodes without cells cultured on them, shown in Figure 4c, using ZView software. The experimental results were well fitted. The electrical responses of cells were simply described by RC circuit, which was commonly used in other studies [35]. The conductivity and relative dielectric constant of cells were $1 \times 10^{-5}(\mathrm{~S} / \mathrm{m})$ and 10 , respectively, and the thickness of the cell membrane was $0.007 \mu \mathrm{m}$ [50]. The intrinsic electrical parameters of the electrodes were not affected by the addition of cells. The model was validated based on total impedance experimental after $24 \mathrm{~h}$ of growth without drug treatment as a function of sweeping frequency, as shown in Figure 10b. In our model, it is assumed that $R_{s}^{\prime}$ and $R_{\text {cell }}$ were proportional to the strength of the cell-substrate adhesion and cell count regulated by chemotherapy drugs. The strength of the cell-substrate adhesion was characterized by the fluorescence intensity of vinculin $(F)$, and the cell count was denoted by the optical density $(O D)$ resulting from the CCK- 8 experiments. Therefore, the total impedance of the cell-electrode system was approximately expressed as follows:

$$
\begin{gathered}
z_{\text {total }}=R_{s} \prime+R_{\text {cell }}+z_{\text {electrode }} \\
z_{\text {total }}=k_{1} F+k_{2} O D+z_{\text {electrode }}
\end{gathered}
$$

Based on the method of the multiple linear regression, the fitted proportionality coefficients, $\mathrm{k} 1$ and $\mathrm{k} 2$, were $2.72 \pm 0.14$ and $109.56 \pm 3.31$. Therefore, $R_{s}^{\prime}$ and $R_{\text {cell }}$ responding to the simulation of dose-dependent DDP, DOX, and 5-FU for $24 \mathrm{~h}$ were shown in Table 1. The model results predicted that cell-cell contact of HeLa cells treated with increased concentrations of DDP, DOX, and 5-FU would be lower compared with the control group, and higher cell-electrode contact of HeLa cells treated with low-dose drugs would be more obvious than HeLa cells treated with high-dose drugs. Therefore, the impedance profiles of HeLa cells responding to the treatment of DDP, DOX, and 5-FU could be regulated by combining the effects of cell-cell and proliferation-related cell-electrode contact.

Table 1. Derived $R_{s}^{\prime}$ and $R_{\text {cell }}$ of HeLa cells treated dose-dependently with DDP, DOX, and 5-FU.

\begin{tabular}{cccccccc}
\hline $\mathrm{R}_{\mathrm{S}}^{\prime}(\Omega)$ & $41.58 \pm 3.71$ & $96.43 \pm 3.86$ & $47.79 \pm 3.99$ & $76.31 \pm 4.19$ & $59.37 \pm 2.7$ & $68.83 \pm 4.15$ & $42.49 \pm 1.35$ \\
\hline $\mathrm{R}_{\text {cell }}(\Omega)$ & $124.74 \pm 1.74$ & $65.54 \pm 3.01$ & $45.81 \pm 2.52$ & $98.73 \pm 3.53$ & $77.47 \pm 1.27$ & $113.37 \pm 5.16$ & $89.82 \pm 0.05$ \\
\hline
\end{tabular}

\section{Conclusions}

In this study, Au interdigitated electrodes were utilized to investigate the impedance profiles of HeLa cells treated with three model drugs (DDP, DOX, and 5-FU). The distinct impedance responses of HeLa cells to different doses of chemotherapy drugs were exhibited. Time-integrated impedance cell index values under different drug treatment stimulations reflected HeLa cell responses under drug treatment. Changes in impedance responses were related with the combination of vinculin-mediated cell adhesion to the substrate and the cell proliferation rate. The values of the adhesion-related resistance and the proliferation-related resistance could be derived from the circuit model based on the method of multilinear regression to demonstrate the distinct weighted roles of cell adhesion and proliferation in impedance responses of HeLa cells under the treatment of DDP, DOX, and 5-FU. The proposed cell index normalization and integration adds new understanding to impedance measurements to more comprehensively reflect the behavioral responses of cells to various stimuli. Our study could facilitate the scientists and clinicians to select more effective schemes for the treatment of the cervical cancer and even other types of cancers based on the specific impedance responses. 
Author Contributions: X.D. was in charge of the design of the whole experimental protocol and the measurement of impedance response of cells under treatment of distinct chemotherapy drugs. Y.L. was in charge of fabrication of the electrodes. J K. was in charge of cell culture and the experiment of immunofluorescence staining. Q.X. designed section structures and produced figures. D.H. and Y.W. review and editing. K.W., H.M., and W.C.: review and editing, project administration, and funding acquisition. All authors have read and agreed to the published version of the manuscript.

Funding: This work was supported by the National Natural Science Foundation of China [No. 11502156, $11632013,61771467,11502158$ and 51503140].

Conflicts of Interest: The authors declare no conflict of interest.

\section{References}

1. Kawai, S.; Suzuki, M.; Arimoto, S.; Korenaga, T.; Yasukawa, T. Determination of membrane capacitance and cytoplasm conductivity by simultaneous electrorotation. Analyst 2020, 145, 4188-4195. [CrossRef]

2. Stanica, L.; Gheorghiu, M.; Stan, M. Quantitative assessment of specific carbonic anhydrase inhibitors effect on hypoxic cells using electrical impedance assays. J. Enzyme Inhib. Med. Chem. 2017, 32, 1079-1090. [CrossRef]

3. Nahid, M.A.; Campbell, C.E.; Fong, K.S.K. An evaluation of the impact of clinical bacterial isolates on epithelial cell monolayer integrity by the electric Cell-Substrate Impedance Sensing (ECIS) method. J. Microbiol. Methods 2020, 169, 105833. [CrossRef] [PubMed]

4. Lee, H.T.; Sharek, L.; O'Brien, E.T. Vinculin and metavinculin exhibit distinct effects on focal adhesion properties, cell migration, and mechanotransduction. PLOS ONE 2019, 14, e0221962. [CrossRef]

5. Gheorghiu, M.; Enciu, A.M.; Popescu, B.O. Functional and Molecular Characterization of the Effect of Amyloid- $\beta 42$ on an in vitro Epithelial Barrier Model. J. Alzheimer Dis. 2014, 38, 787-798. [CrossRef]

6. Olmo, A.; Yuste, Y.; Serrano, J.A. Electrical Modeling of the Growth and Differentiation of Skeletal Myoblasts Cell Cultures for Tissue Engineering. Sensors 2020, 20, 3152. [CrossRef]

7. Wang, L.; Yin, H.; Xing, W.; Yu, Z.; Guo, M.; Cheng, J. Real-time, label-free monitoring of the cell cycle with a cellular impedance sensing chip. Biosens. Bioelectron. 2010, 25, 990-995. [CrossRef]

8. Láng, O.; Kőhidai, L.; Wegener, J. Label-free profiling of cell dynamics: A sequence of impedance-based assays to estimate tumor cell invasiveness in vitro. Exp. Cell Res. 2017, 359, 243-250. [CrossRef]

9. Wei, M.; Zhang, Y.; Li, G. A cell viability assessment approach based on electrical wound-healing impedance characteristics. Biosens. Bioelectron. 2019, 124, 25-32. [CrossRef] [PubMed]

10. Tran, T.B.; Baek, C.; Min, J. Electric cell-substrate impedance sensing (ecis) with microelectrode arrays for investigation of cancer cell-Fibroblasts interaction. PLOS ONE 2016, 11, e0153813. [CrossRef]

11. Pradhan, R.; Rajput, S.; Mandal, M.; Mitra, A.; Das, S. Frequency dependent impedimetric cytotoxic evaluation of anticancer drug on breast cancer cell. Biosens. Bioelectron. 2014, 55, 44-50. [CrossRef] [PubMed]

12. Wang, H.; Wang, L.; Mitchelson, K.; Yu, Z.; Cheng, J. Analysis of the sensitivity and frequency characteristics of coplanar electrical cell-substrate impedance sensors. Biosens. Bioelectron. 2008, 24, 14-21. [CrossRef]

13. Mansor, A.F.M.; Abbas, P.; Hamdan, T.H. Toxicity studies of agarwood essential oil in vero cells using electrical impedance sensor. Malays. J. Fundam. Appl. Sci. 2017, 13, 540-545. [CrossRef]

14. Parekh, A.; Das, D.; Das, S. Bioimpedimetric analysis in conjunction with growth dynamics to differentiate aggressiveness of cancer cells. Sci. Rep. 2018, 8, 783. [CrossRef] [PubMed]

15. Heijink, I.H.; Brandenburg, S.M.; Noordhoek, J.A. Characterisation of cell adhesion in airway epithelial cell types using electric cell-substrate impedance sensing. Eur. Respi. J. 2010, 35, 894-903. [CrossRef]

16. Dasari, S.; Bernard Tchounwou, P. Cisplatin in cancer therapy: Molecular mechanisms of action. Eur. J. Pharmacol. 2014, 740, 364-378. [CrossRef]

17. Mohan, P.; Rapoport, N. Doxorubicin as a molecular nanotheranostic agent: Effect of doxorubicin encapsulation in micelles or nanoemulsions on the ultrasound-mediated intracellular delivery and nuclear trafficking. Mol. Pharm. 2010, 7, 1959-1973. [CrossRef]

18. Sarder, A.; Rabbani, M.G.; Chowdhury, A.S.M.H.K. Molecular basis of drug interactions of methotrexate, cyclophosphamide and 5-fluorouracil as chemotherapeutic agents in cancer. Biomed. Res. Ther. 2015, 2, 196-206. [CrossRef]

19. Zhikhoreva, A.A.; Belashov, A.V.; Bespalov, V.G. Morphological changes in the ovarian carcinoma cells of Wistar rats induced by chemotherapy with cisplatin and dioxadet. Biomed. Opt. Express 2018, 9, 5817-5827. [CrossRef]

20. Dhahi, R.M. In Vitro Design of Preclinical Models for Chemotherapy Combinations in Human Breast Tumours. J. Clin. Diagn. Res. 2019, 13, FC05-FC08. [CrossRef]

21. Lukyanova, N.Y.; Rusetskya, N.V.; Tregubova, N.A. Molecular and cell cycle in MCF-7 cells resistant to cisplatin and doxorubicin. Exp. Oncol. 2009, 31, 87-91.

22. Mansor, A.F.M.; Nordin, A.N. Theoretical Modelling of Interdigitated Electrode Sensor for Mammalian Cell Characterization. In Proceedings of the 2018 7th International Conference on Computer and Communication Engineering (ICCCE), Kuala Lampur, Malaysia, 19-20 September 2018. 
23. Rahman, M.S.A.; Mukhopadhyay, S.C.; Yu, P.L. Novel Sensors for Food Inspection: Modelling, Fabrication and Experimentation; Springer International Publishing: New York, NY, USA, 2014.

24. Ibrahim, M.; Claudel, J.; Kourtiche, D. Geometric parameters optimization of planar interdigitated electrodes for bioimpedance spectroscopy. J. Electr. Bioimped. 2013, 4, 13-22. [CrossRef]

25. Lai, Y.-T.; Chu, Y.-S.; Lo, J.-C.; Hung, Y.-H.; Lo, C.-M. Effects of electrode diameter on the detection sensitivity and frequency characteristics of electric cell-substrate impedance sensing. Sens. Actuators B Chem. 2019, 288, 707-715. [CrossRef]

26. Ahmed, M.; Jamil, K. Cytotoxicity of neoplastic drugs gefitinib, cisplatin, 5-fu, gemcitabine, and vinorelbine on human cervical cancer cells (hela). Biol. Med. 2011, 3, 60-71.

27. Fourre, N.; Millerot-Serrurot, E.; Garnotel, R. Extracellular matrix proteins protect human ht1080 cells against the antimigratory effect of doxorubicin. Cancer Sci. 2008, 99, 1699-1705. [CrossRef] [PubMed]

28. Gao, L.; Shen, L.; Yu, M. Colon cancer cells treated with 5-fluorouracil exhibit changes in polylactosamine-type N-glycans. Mol. Med. Rep. 2014, 9, 1697-1702. [CrossRef]

29. Rahim, S.; Uren, A. A real-time electrical impedance based technique to measure invasion of endothelial cell monolayer by cancer cells. J. Vis. Exp. 2011, 50, 2792. [CrossRef]

30. Mansor, A.F.M.; Ibrahim, I.; Zainuddin, A.A. Modeling and development of screen-printed impedance biosensor for cytotoxicity studies of lung carcinoma cells. Med. Biol. Eng. Comput. 2018, 56, 173-181. [CrossRef] [PubMed]

31. Atienzar, F.A.; Tilmant, K.; Gerets, H.H. The Use of Real-Time Cell Analyzer Technology in Drug Discovery. J. Biomol. Screen. 2011, 16, 575-587. [CrossRef]

32. Ke, N.; Nguyen, K.; Irelan, J. Multidimensional GPCR profiling and screening using impedance-based label-free and real-time assay. Methods Mol. Biol. 2015, 1272, 215.

33. Atienza, J.M. Label-free and real-time cell-based kinase assay for screening selective and potent receptor tyrosine kinase inhibitors using microelectronic sensor array. J. Biomol. Screen. 2006, 11, 634. [CrossRef]

34. Puskás, L.G. A cell-microelectronic sensing technique for the screening of cytoprotective compounds. Int. J. Mol. Med. 2010, 25, 4. [CrossRef] [PubMed]

35. Adcock, A.F.; Agbai, C.O.; Yang, L. Application of electric cell-substrate impedance sensing toward personalized anti-cancer therapeutic selection. J. Anal. Sci. Technol. 2018, 9, 1-11. [CrossRef]

36. Xu, H.; Duan, J.; Ren, L.; Yang, P.; Yang, R.; Li, W.; Zhao, D.; Shang, P.; Jiang, J.X. Impact of flow shear stress on morphology of osteoblast-like IDG-SW3 cells. J. Bone Miner. Metab. 2018, 36, 529-536. [CrossRef] [PubMed]

37. Jansen, K.; Atherton, P.; Ballestrem, C. Mechanotransduction at the cell-matrix interface. Semin. Cell Dev. Biol. 2017, 71, 75-83. [CrossRef] [PubMed]

38. Thievessen, I.; Fakhri, N.; Steinwachs, J.; Kraus, V.; McIsaac, R.S.; Gao, L.; Chen, B.; Baird, M.A.; Davidson, M.W.; Betzig, E.; et al. Vinculin is required for cell polarization, migration, and extracellular matrix remodeling in 3D collagen. FASEB J. 2015, 29, 4555-4567. [CrossRef]

39. Rothenberg, K.E.; Scott, D.W.; Christoforou, N. Vinculin force-sensitive dynamics at focal adhesions enable effective directed cell migration. Biophys. J. 2018, 114, 1680-1694. [CrossRef]

40. Izard, T.; Brown, D.T. Mechanisms and functions of vinculin interactions with phospholipids at cell adhesion sites. J. Biol. Chem. 2016, 291, 2548-2555. [CrossRef]

41. Zhu, X.; Ouyang, Y.; Zhong, F. Silencing of ckip-1 promotes tumor proliferation and cell adhesion-mediated drug resistance via regulating akt activity in non-hodgkin's lymphoma. Oncol. Rep. 2017, 37, 622-630. [CrossRef]

42. Zhang, Y.; Wu, Z.; Yu, H. Chinese herbal medicine wenxia changfu formula reverses cell adhesion-mediated drug resistance via the integrin $\beta 1$-pi3k-akt pathway in lung cancer. J. Cancer 2019, 10, 293-304. [CrossRef]

43. Piska, K.; Koczurkiewicz, P.; Wnuk, D. Synergistic anticancer activity of doxorubicin and piperlongumine on du-145 prostate cancer cells-The involvement of carbonyl reductase 1 inhibition. Chem. Biol. Interact. 2019, 300, 40-48. [CrossRef] [PubMed]

44. Yu, Q.; Xu, L.; Chen, L.; Sun, B.; Yang, Z.; Lu, K.; Yang, Z. Vinculin expression in non-small cell lung cancer. J. Int. Med. Res. 2020, 48, 1-9. [CrossRef]

45. Ziegler, W.H.; Liddington, R.C.; Critchley, D.R. The structure and regulation of vinculin. Trends Cell Biol. 2006, 16, 453-460. [CrossRef] [PubMed]

46. Giaever, I.; Keese, C.R. Micromotion of mammalian cells measured electrically. Proc. Natl. Acad. Sci. USA 1991, 88, 7896-7900. [CrossRef]

47. Huang, X.; Nguyen, D.; Greve, D.W. Simulation of microelectrode impedance changes due to cell growth. IEEE Sens. J. 2004, 4, 576-583. [CrossRef]

48. Vyas, R.N.; Li, K.; Wang, B. Modifying randles circuit for analysis of polyoxometalate layer-by-layer films. J. Phys. Chem. B 2010, 114, 15818-15824. [CrossRef] [PubMed]

49. Schoenbach, K.H.; Hargrave, B.Y.; Joshi, R.P. Bioelectric effects of intense nanosecond pulses. IEEE Trans. Dielectr. Electr. Insul. 2007, 14, 1088-1109. [CrossRef]

50. Yao, C.; Mi, Y.; Li, C. Study of transmembrane potentials on cellular inner and outer membrane-Frequency response model and its filter characteristic simulation. IEEE Trans. Biomed. Eng. 2008, 55, 1792-1799. [PubMed] 